\title{
Estratégia\&Negócios
}

ISSN 1984-3372

http://www.portaldeperiodicos.unisul.br/index.php/EeN/

\section{COMUNICAÇÃO E CONSTRUÇÃO DO SIGNIFICADO EM MUDANÇAS ORGANIZACIONAIS PLANEJADAS}

\section{COMMUNICATION AND MEANING CONSTRUCTION IN PLANNED ORGANIZATIONAL CHANGES: THE EMPLOYEE PERCEPTIONS OF A BRAZILIAN GOVERNMENTAL ORGANIZATION}

\section{Tindyua de Moraes Nogueira}

Analista em ciência e tecnologia da Comissão Nacional de Energia Nuclear.

Mestrado em Administração de Empresas pela Pontifícia Universidade Católica do Rio de Janeiro.

E-mail: tindynog@hotmail.com

\section{Patricia Amelia Tomei}

Professora associada da Pontifícia Universidade Católica do Rio de Janeiro/IAG. Doutorado em doutorado sandwich New School for Social Research e Doutorado em Administração pela Universidade de São Paulo.

E-mail: patomei@iag.puc-rio.br

Recebido em 14/03/2013. Aprovado em 18/07/2013. Disponibilizado em 30/08/2013. Avaliado pelo Sistema double blind review

R. eletr. estrat. neg., Florianópolis, v.6, n.2, p. 175-214, mai./ago. 2013.

http://portaldeperiodicos.unisul.br/index.php/EeN/index
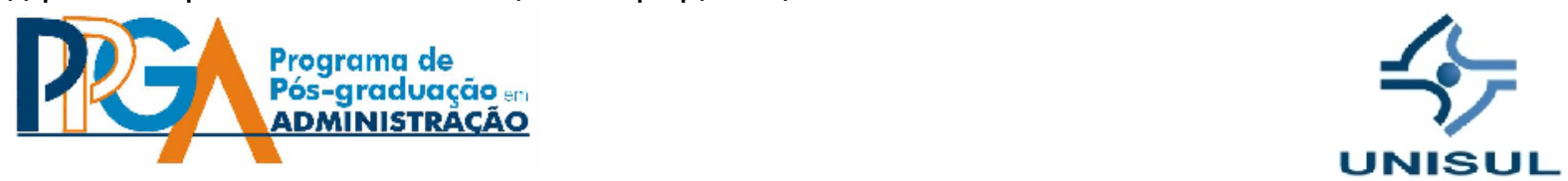

CCopyright 2008 UNISUL-PPGA/Estratégia e Negócios. Todos os direitos reservados. Permitida citação parcial, desde que identificada a fonte. Proibida a reprodução total. Em caso de dúvidas, consulte o editor:

ademar.unisul@gmail.com; (48) 3229-193 


\section{RESUMO}

Muitos pesquisadores e gerentes têm se empenhado na busca pela descoberta dos fatores que afetam o sucesso dos processos de mudança organizacional. Um dos fatores mais apontados na literatura sobre esse tema diz respeito à "resistência" à mudança por parte de alguns atores organizacionais, em especial os pertencentes aos níveis hierárquicos mais baixos. Mas como será que esses indivíduos percebem a si mesmos e aos outros em um processo de mudança organizacional? Como eles percebem o conteúdo e o gerenciamento da mudança? Qual o papel da comunicação nesse contexto? O presente trabalho contribui para um melhor entendimento sobre o processo de construção do significado para indivíduos e grupos em mudanças organizacionais planejadas e sua relação com a comunicação e os aspectos comportamentais apresentados por eles. Para tanto, foi conduzido um estudo de caso em uma empresa estatal brasileira que estava passando por um processo de intervenção organizacional na área de Tecnologia da Informação: implantação de um sistema de gerenciamento eletrônico de documentos e do fluxo de trabalho. A metodologia da pesquisa baseou-se na análise de questionários e entrevistas semiestruturadas aplicadas aos empregados da base e na observação-participante dos pesquisadores, utilizando-se, para tanto, o método Pesquisa-ação (THIOLLENT, 2005), cuja adoção justifica-se pelo alto grau de envolvimento do autor com o projeto em estudo. Os resultados comprovam que a mudança organizacional é sensível ao aspecto relacional e temporal e que a ação e o comportamento humano devem ser considerados como frutos da comunicação e fator determinante na construção dos significados e das identidades individuais e coletivas.

Palavras-chave: Mudança Organizacional. Comunicação Organizacional. Resistência à Mudança. Construção do Significado. Identidade Organizacional. 


\section{INTRODUÇÃO}

As mudanças organizacionais têm sido alvo de extensa literatura com grande variedade de abordagens e enfoques (NONAS, 2005; WOOD, 2009). A gestão da mudança, dessa forma, não pode ser explicada por um único modelo e perspectiva.

Para a análise da mudança no ambiente organizacional, é preciso entender o quadro multifacetado que reflete recortes diferentes, de acordo com o ângulo de visão do estudo de Costa (2006). Conforme colocam Sirkin, Keenan e Jackson (2005) e Vince e Broussine (1996), quanto mais as coisas mudam, mais elas ficam iguais, já que, na maioria dos processos de mudança, não se considera a complexidade, a ambiguidade e os paradoxos que se instalam no ambiente organizacional.

A dificuldade que as organizações sentem em realizar mudanças e que a literatura enfrenta em explicá-las, muitas vezes, está relacionada à ênfase exagerada na racionalidade dos processos de gestão de mudanças que é tida como simplista por reduzir o indivíduo a mero figurante (BEER; NOHRIA, 2000; BOVEY; HEDE, 2001; GEORGE; JONES, 2001; HOLBECHE, 2006; SOUMYAJA; KAMALANABHAN; BHATTACHARYYA, 2011; TOWNLEY, 2008).

Essa crítica à visão racional reducionista e simplista da mudança organizacional tem favorecido pesquisas focadas em pessoas, onde se aborda a importância do papel do indivíduo, de seus sentimentos, suas atitudes, seus comportamentos e suas emoções como agentes, facilitadores e responsáveis pelo sucesso da mudança (GEORGE; JONES, 2001; ANTONI, 2004; WANBERG; BANAS, 2000; VAKOLA; NIKOLAOU, 2005; HUY, 1999; CHRUSCIEL, 2006; HERKENHOFF, 2004).

Para a implantação de uma mudança organizacional com base nessa lógica interativa que leva em conta a ação social na organização e as pessoas que dela participam (WEICK; QUINN, 1999), é preciso que os membros envolvidos na mudança compreendam, internalizem e adotem os seus objetivos (SILVA, 2001; WANBERG; BANAS, 2000). Para tanto, é praticamente consenso na literatura que a comunicação da mudança é o primeiro mecanismo para a criação da disponibilidade de mudar entre os indivíduos, atuando como ferramenta para veicular informação, criar entendimentos, compartilhar experiências e R. eletr. estrat. neg., Florianópolis, v.6, n.2, p. 177-216, mai./ago. 2013 
elaborar sentidos. Em casos em que o processo de comunicação é falho, os ruídos e boatos exacerbam os aspectos negativos da mudança e aumentam a resistência (BECHER, 2003; WANBERG; BANAS, 2000; REICHERS et al., 1997; ARMENAKIS; HARRIS, 2002; BERNERTH, 2004).

Diante do exposto, podemos concluir que para entendermos o processo de mudança em uma organização é fundamental focarmos o indivíduo que se envolve no contexto de mudança, já que a forma como os indivíduos constroem o significado da mudança afeta significativamente seus resultados (PARISH; CADWALLADER; BUSCH, 2008; BALOGUN, 2006; STENSAKER; FALKENBERG, 2007).

A partir dessa premissa, o presente trabalho tem como objetivo contribuir para um melhor entendimento sobre o processo de construção do significado para indivíduos e grupos inseridos em um contexto de mudança organizacional planejada, por meio da análise dos sentimentos e das emoções por eles experimentadas, tais como: medo, ansiedade, insegurança, violação do contrato psicológico, justiça procedural, percepção de oportunidades e ameaças.

Para tanto, após um breve referencial teórico sobre a questão da resistência à mudança, e sobre o papel da comunicação na construção dos significados, foi analisado o caso de uma empresa estatal brasileira que atua na área de energia nuclear, a qual foi submetida a uma intervenção organizacional na área de Tecnologia da Informação: a implantação de um sistema de gerenciamento eletrônico de documentos e do fluxo de trabalho (GED/WF).

\section{O PAPEL DO INDIVÍDUO NO PROCESSO DE MUDANÇA E A QUESTÃO DA RESISTÊNCIA}

A mudança organizacional é uma atividade constante nas empresas, visto que estas, mesmo que ocupem uma fatia dominante em sua área de atuação, têm de se adiantar às pressões de um ambiente cada dia mais global e competitivo (WOOD, 2009; IGBAL, 2011; BANUTU-GOMEZ, 2007; KOTTER; COHEN, 2002; SHOOK; ROTH, 2011; JIMMIESON et al., 2004). 
Apesar de frequentes, os processos de mudança organizacional nem sempre estão associados a sucessos, e uma explicação frequente do porquê dos esforços frustrados tangenciar a questão da resistência dos indivíduos (PIDERIT, 2000; BORDIA et al., 2004; ARMENAKIS; HARRIS, 2002; OREG, 2006).

Segundo as pesquisas de Maurer et. al. (1996), em torno de metade a dois terços de todas as empresas nas quais os esforços de mudança falham, a resistência é pouco reconhecida, mas considerada criticamente um contribuinte importante daquele fracasso, reforçando o aspecto ambíguo da resistência à mudança: se por um lado ela é necessária para garantir estabilidade e previsibilidade à organização, por outro, ela ameaça a capacidade de adaptação e de incremento da competitividade organizacional.

Conceitualmente, a ideia de resistência às mudanças organizacionais é creditada a Lewin (1947), que afirma que as organizações são sistemas em equilíbrio quaseestacionário, sujeitos a forças opostas de mesma intensidade que os mantêm em estado de equilíbrio, status quo, isto é, a organização seria um sistema sujeito a um conjunto de forças opostas, mas de mesma intensidade, que mantêm o sistema em equilíbrio ao longo do tempo.

Esses processos não estariam em equilíbrio constante, porém mostrariam flutuações ao redor de um determinado nível. As mudanças ocorreriam quando uma das forças superasse a outra em intensidade, deslocando o equilíbrio para um novo patamar. Assim, a resistência à mudança seria o resultado da tendência de um indivíduo ou de um grupo a se opor às forças sociais que objetivam conduzir o sistema para um novo patamar de equilíbrio, relacionado a sentimentos de incerteza, ansiedade e medo (HERNANDEZ; CALDAS, 2001; VAKOLA; NIKOLAOU, 2005).

Para a melhor compreensão da resistência à mudança nas organizações, vários autores enfatizaram alguns elementos envolvidos na questão, como a reação dos indivíduos para a manutenção do status quo (KIRSCH; CHELLIAH; PARRY, 2011; KOHLER; MUNZ; GRAWITCH, 2006; GIANGRECCO;PECCEI,2005; CONNER 1995), o medo do desconhecido e os sentimentos de ameaça à situação familiar (BOVEY; HEDE, 2001; ROBBINS; JUDGE; SOBRAL, 2011; COGHLAN, 1993), a perda do poder e do controle (BUCHANAN, 2008; CLEGG, 1994; JERMIER; KNIGHTS; NORD, 1994; PIDERIT, 2000), a questão da cultura organizacional 
(KAVANAGH; ASHKANASY, 2006; RAFFERTY; RESTUBOG, 2010) e outras questões comportamentais e emocionais, como prontidão, comprometimento, ansiedade, agitação e depressão (DYCK; CARON; ARON, 2006; BORDIA et al., 2004, HERSCOVITCH; MEYER, 2002; BROWER; ABOLAFIA, 1995; JIAN, 2007; ASHFORTH; MAEL, 1998; STANLEY; MEYER; TOPOLNYTSKY, 2005).

A abordagem da mudança organizacional no campo das emoções teve o seu primeiro estudo empírico realizado por Coch e French (1948), que acreditavam que o seu fracasso poderia estar relacionado a muitos fatores, mas nenhum tão importante quanto às reações emocionais do empregado.

Segundo Hernandez e Caldas (2001), esse estudo influenciou grande parte da literatura que se seguiu sobre o tema e continuou a despertar interesse dos pesquisadores atuais, os quais introduziram novas abordagens da resistência à mudança de forma multifacetada (CHENG; PETROVIC-LAZAREVIC, 2005) com componentes cognitivos e afetivos operando simultaneamente, destacando o papel das reações emocionais na forma como os indivíduos constroem significados e conferem sentido ao mundo social e organizacional (NEIVA, 2004; GEORGE; JONES, 2001; ROULEAU, 2005; RANDALL; PROCTER, 2008; SCHWARZ; WATSON; CALLAN, 2005; WHELAN-BERRY; GORDON; HININGS, 2003).

Nessas pesquisas, as pessoas não são apenas seres lógicos e racionais, que mudam seu comportamento de acordo com interesses e informações, mas indivíduos que têm expectativas, desejos, fantasias, processos internos e inconscientes (SILVA, 2001; VINCE; BROUSSINE, 1996; GABRIEL, 2000).

Conforme coloca Lines (2005), essas emoções determinam o conteúdo e a força propulsora da mudança, atuando como um impulso que influencia a busca consistente de informações em apoio às reações emocionais que podem ser manifestadas de várias formas, como o silêncio organizacional, que muitas vezes inviabiliza o fluxo de informações necessário para a tomada de decisão e dificulta o aprendizado de erros, favorecendo sintomas de pensamento grupal (GLADWELL, 2005; BARON, 2005; MORRISON; MILLIKEN, 2000); o ceticismo e o cinismo (REICHERS et al., 1997; DIAS, 2011; NAUS; ITERSON, ROE, 2007), o clima de desconfiança (TUSHMAN; ROMANELLI, 1985) e a quebra de contratos implícitos e psicológicos (ROUSSEAU, 1989; INALHAN, 2009; MILLIGAN, 2003). 
Além desses, outros autores teceram críticas aos modelos tradicionais que tratam do tema resistência à mudança de forma limitada e simplista e, portanto, vêm procurando aprimorar ou desenvolver novos modelos com foco mais amplo sobre o processo emocional e comportamental da mudança.

O presente trabalho utilizou uma abordagem ampliada da questão social da mudança na medida em que se propôs a estudar o comportamento dos indivíduos e grupos sob uma ótica relacional, considerando o contexto da mudança e sua relação com as percepções e construções de significado para os mesmos.

\section{A CONSTRUÇÃO DO SIGNIFICADO DA MUDANÇA ORGANIZACIONAL E O PAPEL DA COMUNICAÇÃO}

Para a mudança ser efetiva, a comunicação não deve apenas transmitir o plano de mudança, mas, sim, criar um significado comum entre os funcionários e a empresa sobre as percepções referentes ao contexto da mudança, isto é, é preciso gerenciar questões como as dificuldades de comunicação dos objetivos definidos pela organização e da compreensão desses objetivos pelos indivíduos (ZORN, 2000; COSTA, 2006; ERTURK, 2008; FRAHM; BROWN, 2007; PETTIGREW; WOODMAN, CAMERON, 2001; JONES et al., 2004; TAYLOR et al., 2001).

A comunicação é um dos principais fatores que afetam as chances de sucesso dos processos de mudança, já que ela posiciona o engajamento ou a resistência das pessoas e favorece a implementação desse processo de significação (BRUTUS; GREGURAS, 2008; SILVA, 2001; FIOL, 2002; GIOIA, SCHULTZ; CORLEY, 2000; JUNIOR; MATEUS; SOUTO, 2008; HOWARD, 2006).

Tendo em vista que as pesquisas apontam para as falhas de comunicação como as fontes mais frequentes de conflitos e resistência por parte dos atores organizacionais, conclui-se que a comunicação exerce um papel importantíssimo na construção do significado da mudança, admitindo-se tanto o sujeito quanto a organização como sendo produtos da comunicação (HOPE, 2010; SONENSHEIN, 2010; MAITLIS; SONENSHEIN, 2010). 
Entretanto, na prática, observa-se que pouca ou nenhuma importância é dada à comunicação organizacional, cuja perspectiva predominante é a instrumental ou mecanicista, segundo a qual cada peça da engrenagem deve ser perfeitamente ajustada, seguindo determinados padrões e regras preestabelecidos e suprimindo todo e qualquer ruído (comunicação não diretamente relacionada ao desempenho das tarefas) que possa comprometer a integridade da informação, de modo que a mensagem seja transmitida e assimilada de forma inequívoca (QUIRKE, 1996; CINITE, DUXBUR; HIGGINS, 2009). Essa perspectiva, dessa forma, ignora a questão do silêncio, definido por Robbins, Judge e Sobral (2011) como a ausência de palavras ou de ruídos, como forma de comunicação no comportamento organizacional.

A perspectiva adotada neste trabalho é a da relação e da construção coletiva de significado e ação, segundo a qual não faz sentido pensar em comunicação e organização como dois conceitos independentes. Do mesmo modo, não faz sentido pensar na existência de uma separação entre os lados formal e informal da organização ou da comunicação organizacional (BRYANT; COX, 2004; ELVING, 2005; FAIRHURST; PUTNAM, 2004; FERNANDES; ZANELLI, 2006)

De acordo com essa perspectiva, a comunicação passa a ser vista em termos do universo das relações que compõem o contexto social da organização e que, ao mesmo tempo, são influenciadas por esse contexto (MAGUIRE; HARDY, 2009).

A análise do discurso dos membros organizacionais é uma dimensão importante no estudo do comportamento humano, pois serve como fonte de diagnóstico da construção de suas identidades, como resultado das múltiplas interpretações dos diálogos e dos relacionamentos dos quais participam (BECHER, 2003; PENTEADO; SILVA, 2004; HOGG; TERRY, 2000; PHILLIPS; LAWRENCE; HARDY, 2004).

O exercício da prática comunicacional é fundamental para a construção e reconstrução das identidades sociais e do próprio significado do trabalho e da mudança para os indivíduos e grupos. A comunicação possibilita o compartilhamento de sentido sobre as experiências vividas por meio do desenvolvimento de uma linguagem comum. A mudança organizacional deve ser vista como um processo emancipatório dos seres humanos, que são agentes competentes ou conhecedores de suas competências e capazes de expressar suas R. eletr. estrat. neg., Florianópolis, v.6, n.2, p. 177-216, mai./ago. 2013 
percepções, sentimentos e emoções por meio por meio do discurso (SCHWARZ; WATSON; CALLAN, 2011; OSWICK et al., 2010).

Assim sendo, a base teórica deste estudo foi fundamentada principalmente na Teoria da Estruturação, proposta por Giddens (1984), que considera todo ator social como sendo um ser reflexivo e consciente, constituindo-se como um ator por meio da interação social que, para o autor, é a principal unidade de análise, visto que é onde ocorre a construção de significado para esses atores.

A Teoria da Estruturação é vista como uma ferramenta muito útil e de grande importância para a análise organizacional, pois permite a vinculação da ação humana à estrutura por meio de um processo dinâmico de construção e reconstrução da vida social, denominado por Giddens (1984) de dualidade da estrutura: uma alternativa ao dualismo, relacionado ao sujeito e ao objeto nas Ciências Sociais, onde a estrutura é tratada como algo externo e limitador da ação dos indivíduos (KORTH, 2002; WELLS, 1995).

Segundo o autor, tratar a estrutura como algo exclusivo e restritivo é o mesmo que considerá-la como variável independente e autônoma em relação à ação humana. Isso significa, na prática, interpretar a ação como sendo unicamente determinada pela estrutura social, não se dando voz aos atores sociais e, portanto, desconsiderando sua capacidade de intervenção na vida social, inclusive sua capacidade de alterar e transformar a própria estrutura. $O$ processo cognitivo das ações humanas pressupõe o conhecimento por parte dos atores sociais dos contextos em que se desenrolam as ações humanas. Esse conhecimento mútuo (mutual knowledge) é compartilhado pelos atores sociais, que sabem como se comportar ou prosseguir em determinadas situações (LAYDER, 1994).

A convivência social concilia condutas e atos de seus agentes sem desconsiderar as estruturas sociais que são referências para aqueles mesmos agentes em processo de interação social.

A interação social constitui a principal unidade de análise para Giddens (1984), pois é onde, segundo ele, ocorre a construção de significado para os atores sociais (COHEN, 1998).

Apesar das críticas referentes às lacunas metodológicas para a aplicação da teoria da estruturação (MORROW; BROWN, 1994; ROSE, 1998), ela apresenta vantagens R. eletr. estrat. neg., Florianópolis, v.6, n.2, p. 177-216, mai./ago. 2013 
analíticas que justificam a sua utilização frequente em estudos empíricos que envolvem as organizações (BAXTER; CHUA, 2003; AHRENS; CHAPMAN, 2002; CONRAD, 2005; JACK, 2005; SOIN et al., 2002; DILLARD; RIGSBY; GOODMAN, 2004).

Assim sendo, tendo como base a teoria da estruturação, Silva (2001) desenvolveu um conjunto de suposições sobre as diferentes dimensões relativas às percepções do indivíduo - no nível de suas interações no dia a dia da ação, da organização e da sociedade como um todo -, que são afetadas pela comunicação organizacional e que influenciam na sua capacidade de assumir a condição de sujeito, bem como de construir suas identidades no contexto da mudança.

Esse conjunto envolve as relações do indivíduo consigo mesmo e com os outros indivíduos presentes nesse contexto, com os quais se sente envolvido em maior ou menor grau, e compreende: (a) o contexto da mudança; (b) a pessoa do entrevistado (o eu) como indivíduo ou como membro da identidade de um grupo; (c) o outro ou os membros dos grupos com os quais, em situações específicas, o indivíduo não percebe identidade comum; (d) a sua relação com o contexto; (e) a sua relação com o outro ou a relação de seu grupo com os outros grupos que possuem identidades distintas; (f) a relação do outro ou dos outros grupos com o contexto; e (g) a comunicação vertical e horizontal na organização.

Esse conjunto de relações que afetam o processo de subjetivação e a reconstrução das identidades dos indivíduos, proposto por Silva (2001), serviu de base para este trabalho, conforme será descrito a seguir.

\section{ASPECTOS METODOLÓGICOS DA PESQUISA}

Para alcançarmos nossos objetivos, foi conduzido um estudo de caso descritivo e exploratório para analisar o processo de construção das identidades e do significado da mudança, para os empregados pertencentes aos níveis hierárquicos mais baixos de um departamento de uma empresa estatal brasileira, durante o processo de implantação de uma mudança organizacional planejada: a implantação de um sistema de gerenciamento eletrônico de documentos e do fluxo de trabalho (GED/WF). 
Foram coletados dados primários por meio da aplicação de questionários e entrevistas semiestruturadas aos funcionários do departamento em estudo em dois momentos marcos da mudança, conforme descrito a seguir:

Quadro 1-Questões utilizadas nas entrevistas semiestruturadas

\begin{tabular}{|c|c|}
\hline Momento 1: Fase inicial (junho/2007) & $\begin{array}{l}\text { Momento 2: três anos e meio depois da implantação } \\
\text { do projeto (agosto/2010) }\end{array}$ \\
\hline $\begin{array}{l}\text { Pouco havia sido feito ou falado sobre a mudança } \\
\text { com a base. }\end{array}$ & $\begin{array}{l}\text { Os processos foram modelados e o programa estava } \\
\text { em vias de implantação. }\end{array}$ \\
\hline $\begin{array}{l}\text { Sujeitos: } 38 \text { Pesquisadores, Analistas e } \\
\text { Tecnólogos. }\end{array}$ & Sujeitos: 57 Pesquisadores, Analistas e Tecnólogos. \\
\hline Respondentes ao questionário: 13. & Respondentes ao questionário: 12. \\
\hline Entrevistados: 0 (zero). & Entrevistados: 10 (dez). \\
\hline
\end{tabular}

Fonte: Dados do autor, 2013.

Os questionários foram encaminhados por meio de correio eletrônico. As entrevistas pessoais, por sua vez, utilizaram-se das mesmas perguntas do questionário e foram conduzidas pelos pesquisadores com cada participante, de modo que favorecessem a exposição de suas percepções e opiniões livremente, recebendo estímulos com novas perguntas ou recondução à resposta por parte dos pesquisadores quando os entrevistados percebessem a necessidade ou considerassem pertinentes a sua intervenção. Uma preocupação presente durante toda a análise foi a de que esta não se limitasse ao que era relatado explicitamente pelos entrevistados. A forma como os discursos eram construídos e as entrelinhas do que era dito pelos profissionais foram elementos essenciais para a análise de suas percepções e para a análise dos resultados da pesquisa, inclusive em seu teor psicológico.

As principais perguntas realizadas por meio de questionários e entrevistas foram:

1. Quando (aproximadamente) e como/por qual meio (exemplos: pela equipe do projeto; pela chefia mediata; pela chefia imediata; pelos demais colegas; por $e$ mail ou outros - especificar) você tomou conhecimento da implantação do GED/WF? 
2. Você participou do processo de implantação do GED/WF, ou seja: participou de algum treinamento/curso sobre o GED/WF? Foi um Especialista ou Técnico do Negócio, fornecendo informações sobre a realização das tarefas ou participou da Homologação/Teste da solução?

3. Em caso positivo: como você avaliaria a sua participação/atuação? Justifique.

4. Em caso negativo: você gostaria de ter participado? Justifique.

5. Você acredita que o GED/WF contribui para um melhor desempenho das suas atividades e/ou para a CGMI como um todo? Justifique.

6. Você acredita que o GED/WF teve algum impacto negativo sobre o desempenho das suas atividades e/ou para a empresa como um todo? Justifique. 7. De forma geral, você se considera otimista ou pessimista com relação à implantação do GED/WF? Justifique.

8. De forma geral, você considera que os demais colegas de trabalho estão otimistas ou pessimistas com relação à implantação do GED/WF? Justifique.

9. Como você avaliaria a participação/atuação das outras partes envolvidas no processo de implantação do GED/WF? (exemplos: chefia mediata, chefia imediata, equipe do projeto, demais colegas etc.). Justifique.

10. Quais conselhos, críticas e/ou sugestões você daria/faria a uma ou mais das partes envolvidas (exemplos: chefia mediata, chefia imediata, equipe do projeto, demais colegas etc.) sobre a implantação do GED/WF?

Os questionários e entrevistas respondidos foram analisados de modo que cada trecho pudesse ser associado a um conceito relativo à narrativa do entrevistado sobre as diferentes dimensões relativas ao contexto da mudança. A partir do conjunto de relações construídas por Silva (2001), foram identificados os seguintes conceitos quanto às percepções dos indivíduos sobre:

a. O CONTEXTO: o contexto externo; a organização antiga; a organização de hoje; a mudança: os eventos e o histórico da mudança e o conteúdo da mudança; 
b. eles mesmos ou sobre seus grupos de identidade (EU/NÓS): quem (como) sou eu/ quem (como) somos nós?

c. o outro ou sobre os grupos com os quais considera que não possui identidade em determinadas situações: quem (como) são os outros (OS OUTROS): os estrangeiros, os donos ou a direção da empresa; os gerentes, os subordinados, os funcionários da outra empresa (em caso de fusão ou de aquisição), os novos, os antigos, os colegas, as pessoas que saíram, os contratados ou terceirizados, os clientes, as pessoas de fora da empresa, a sociedade, a família;

d. a sua situação (ou a situação de seu grupo identitário) no contexto das mudanças (EU/NÓS E O CONTEXTO): a minha (a nossa) consciência sobre o contexto; a minha (a nossa) preparação para o contexto; o perfil necessário para o contexto; a compatibilidade das minhas (das nossas) ideias e valores com o contexto; o meu (o nosso) sentimento no contexto; o meu (o nosso) papel no contexto; o tratamento que recebi (recebemos) no contexto; as minhas (nossas) chances e oportunidades no contexto; a minha (nossa) adaptação ao contexto; as minhas (nossas) expectativas com relação ao contexto; a minha (nossa) situação atual no contexto;

e. as suas relações com o outro, ou as relações de seu grupo de identidade com os outros grupos (EU/NÓS E OS OUTROS): Eu (nós) e os estrangeiros; Eu (nós) e os donos ou a direção da empresa; Eu (nós) e os superiores; Eu (nós) e os subordinados; Eu (nós) e os funcionários da outra empresa; Eu (nós) e os novos; Eu (nós) e os antigos; O nosso relacionamento interpessoal em geral; Eu (nós) e as pessoas que saíram; Eu (nós) e os contratados ou terceirizados; Eu (nós) e os clientes; Eu (nós) e as pessoas de fora da empresa, a sociedade, a família;

f. a relação do outro (ou dos outros grupos) com o contexto (OS OUTROS E O CONTEXTO): os estrangeiros e o contexto; os donos ou a direção da empresa e o contexto; o gerente e o contexto; os subordinados e o contexto; os funcionários da outra empresa e o contexto; os novos e o contexto; os antigos e o contexto; os colegas e o contexto; as pessoas que saíram e o contexto; os contratados e 
terceirizados e o contexto; os clientes e o contexto; as pessoas de fora da empresa, a sociedade, a família e o contexto;

g. os elementos relativos ao modo como acontece a comunicação vertical na organização: a comunicação institucional sobre a mudança; a comunicação institucional no dia a dia; a abertura a opiniões e à participação; e

h. os elementos relativos ao modo como acontece a comunicação horizontal na organização: a comunicação interpessoal; os meios físicos; a comunicação entre áreas.

A análise também incluiu dados obtidos por meio de observação-participante dos pesquisadores ("rádio corredor", reuniões formais e informais com a equipe do projeto e a alta gerência e depoimentos espontâneos provindos de relacionamentos informais). 0 método Pesquisa-ação (THIOLLENT, 2005) foi escolhido intencionalmente devido ao alto grau de envolvimento de um dos pesquisadores com a organização estudada, que atuou como um dos gerentes do projeto de mudança, com poder para intervenções ao longo do processo.

Por fim, tanto para a análise dos discursos, quanto para os dados quantitativos e as informações coletadas via observação participante, foi utilizada uma ótica relacional, ou seja, foram embasadas na premissa de que o processo de constituição do sujeito e de reconstrução de suas identidades pessoais e sociais pode ser compreendido em termos da influência de um amplo conjunto de relações que podem ser afetadas pelas mudanças organizacionais.

\section{RESULTADOS}

Com base no discurso dos empregados, foi possível identificar os diferentes significados e percepções não somente por eles atribuídos ao cenário de mudança em estudo, mas também à organização e aos "outros". Essa seção apresenta um resumo dos principais eventos, sentimentos e percepções dos indivíduos, nos dois momentos de coleta 
de dados, a fim de propiciar um melhor entendimento longitudinal. O Quadro 2, a seguir, apresenta um panorama geral dos dois momentos analisados.

Quadro 2 - Panorama Geral: caracterização dos contextos de mudança

\section{Momento 1 (junho/2007)}

Incerteza sobre reeleição de Lula levou a alta gerência a um estado de insegurança com relação à possibilidade de perda do status quo. Choque de culturas com a chegada de novos servidores (concursados + provenientes de outros departamentos/unidades da empresa).

Arrochos salariais e greves (desmotivação, desânimo e apatia).

Poucos servidores da base envolvidos no projeto por conta da própria metodologia.

Fonte: Elaborado pelos autores, 2013.

\section{Momento 2 (agosto/2010)}

Mais de três anos decorridos após a primeira coleta de dados qualitativos.

$40 \%$ da base envolvida no projeto.

Boatos sobre a criação da Agência Nuclear Brasileira.

Migração em massa de servidores.

Conflitos culturais entre os diferentes grupos sociais.

Ameaça ao status quo.

Clima de euforia: reajustes salariais.

Como podemos observar, a partir das informações do Quadro 2, transcorridos mais de três anos entre uma coleta de dados e outra, os cenários nos dois momentos parecem bem distintos e peculiares, tanto com relação aos aspectos políticos e econômicos, quanto ao surgimento de conflitos e mudanças estruturais internas no departamento da organização em estudo. A mudança evoluiu de uma percepção de clima de greve, com arrocho salarial e apatia, para uma euforia após os reajustes salariais obtidos e diante da perspectiva de mudança de status quo do departamento (que poderia ser transformado na tão desejada Agência Nacional Brasileira de Energia Nuclear).

No quadro seguinte, resumimos as percepções e discursos dos funcionários com relação ao contexto, às suas identidades, aos outros e à comunicação nos dois momentos de coleta de dados.

Quadro 3 - Percepções e discursos dos funcionários

\begin{tabular}{|c|c|}
\hline Momento 1 (junho/2007) & Momento 2 (agosto/ 2010) \\
\hline CONTEXTO & \\
\hline $\begin{array}{l}\text { Desconhecimento sobre os objetivos e } \\
\text { características da mudança. }\end{array}$ & $\begin{array}{l}\text { Desconhecimento sobre os objetivos e características da } \\
\text { mudança. }\end{array}$ \\
\hline $\begin{array}{l}\text { Sentimentos predominantes: pessimismo, } \\
\text { desconfiança e medo (a mudança como "bicho- } \\
\text { papão"). } \\
\text { Descrença no sucesso e na continuidade do projeto }\end{array}$ & $\begin{array}{l}\text { Sentimentos predominantes: ceticismo, desconfiança, } \\
\text { ironia ("Jegue/WF"). } \\
\text { Descrença no sucesso e na continuidade do projeto devido } \\
\text { às experiências vividas no passado aumenta com atrasos e }\end{array}$ \\
\hline
\end{tabular}




\begin{tabular}{|c|c|}
\hline $\begin{array}{l}\text { devido às experiências vividas no passado. } \\
\text { A mudança vista como um "modismo" e para a } \\
\text { promoção gerencial. } \\
\text { A empresa não está preparada para a mudança. }\end{array}$ & $\begin{array}{l}\text { problemas com o projeto. } \\
\text { Reforço da visão da mudança como um "modismo". } \\
\text { Reforço da crença de que a empresa não está preparada } \\
\text { para a mudança. }\end{array}$ \\
\hline $\begin{array}{l}\text { EU/NÓS E O CONTEXTO } \\
\text { Mudança imposta pela organização. } \\
\text { Indivíduos como coadjuvantes, "fantoches" e } \\
\text { "ventríloquos" no processo de mudança. } \\
\text { Sentimentos de exclusão e controle. }\end{array}$ & $\begin{array}{l}\text { EU/NÓS E O CONTEXTO } \\
\text { Mudança imposta pela organização. } \\
\text { Indivíduos como coadjuvantes no processo de mudança. } \\
\text { Sentimentos de exclusão e controle. }\end{array}$ \\
\hline $\begin{array}{l}\text { EU/NÓS E OS OUTROS } \\
\text { ALTA GERÊNCIA } \\
\text { Sentimentos predominantes: autoritarismo, } \\
\text { imposição, controle. } \\
\text { Alta gerência vista como a maior beneficiada com o } \\
\text { projeto. } \\
\text { OUTROS COLEGAS } \\
\text { A maioria se diz pessimista, e também vê os demais } \\
\text { colegas como pessimistas. } \\
\text { EQUIPE DO PROJETO } \\
\text { Retrabalho. } \\
\text { Desafio em lidar com as resistências e cultura } \\
\text { organizacional. }\end{array}$ & $\begin{array}{l}\text { EU/NÓS E OS OUTROS } \\
\text { ALTA GERÊNCIA } \\
\text { Sentimentos predominantes: autoritarismo, imposição, } \\
\text { controle. } \\
\text { Alta gerência vista como a maior beneficiada com o projeto. } \\
\text { GED/WF como ferramenta de justiça no trabalho. } \\
\text { OUTROS COLEGAS } \\
\text { A maioria se diz cética e vê os outros como pessimistas. } \\
\text { EQUIPE DO PROJETO } \\
\text { Reconhecimento à dedicação. } \\
\text { Amadorismo: "consultoria tupiniquim". } \\
\text { Descrença na competência da equipe. }\end{array}$ \\
\hline $\begin{array}{l}\text { COMUNICAÇÃO } \\
\text { Falha, escassa; Rádio-corredor despontando } \\
\text { "Canto da sereia”;“Palavras-chavões” } \\
\text { Alienação }\end{array}$ & $\begin{array}{l}\text { COMUNICAÇÃO } \\
\text { Falha, escassa e ineficiente. } \\
\text { GED/WF = caixinha preta. } \\
\text { Rádio-corredor a pleno vapor. }\end{array}$ \\
\hline
\end{tabular}

Fonte: Elaborado pelos autores, 2013.

\subsection{O CONTEXTO}

Observando o Quadro, 3 percebe-se que os discursos dos funcionários nos dois momentos com relação ao contexto da mudança parecem inalterados, ou seja, mesmo transcorridos mais de três anos desde a primeira coleta, e ainda contando com uma participação mais representativa de funcionários da base. Verificou-se que ainda é predominante o discurso do desconhecimento sobre os objetivos do projeto e também a existência dos sentimentos de desconfiança e descrença no sucesso e continuidade do projeto, muito embora, em um primeiro momento, esse sentimento estivesse atrelado somente às experiências vividas no passado, enquanto que em um segundo momento, esse sentimento também ganhasse reforço com os problemas e dificuldades do próprio projeto. A descrença no sucesso do projeto manifestou-se, inclusive, por meio de deboches e piadas com relação ao GED/WF, que foi carinhosamente apelidado de JEGUE pela base. Evidenciouse, também, uma característica da identidade organizacional, na medida em que pareceu R. eletr. estrat. neg., Florianópolis, v.6, n.2, p. 177-216, mai./ago. 2013 
fazer parte da cultura da empresa um padrão de comportamento da descontinuidade dos projetos, conforme mostram os depoimentos a seguir, transcritos das entrevistas semiestruturadas com os funcionários:

"Estou pessimista, não só pelo que foi dito acima, como porque sabemos que no serviço público projetos tendem a ser descontinuados."

"Pessimista. Se for como tudo na casa, que tem início e é interrompido, sem treinamento adequado, creio que será negativo."

“As pessoas estão meio descrentes devido às tentativas frustradas no passado."

Foi predominante, dessa forma, a visão de que a empresa não estava preparada para a mudança e a de que esta era imposta pela organização, conforme podemos constatar nos dois trechos das entrevistas semiestruturadas com os funcionários transcritos abaixo:

\footnotetext{
"Olha... eu acho difícil, viu? Porque eu estou trabalhando com um computador velho sem infraestrutura de hardware e querendo instalar uma coisa com uma beleza... Uma funcionalidade que não vai ser compatível com o que você tem em cima da sua mesa (referindo-se ao seu próprio computador) não vai dar, não. Infelizmente, não. Um elefante pra colocar num fusquinha... É o mesmo que comprar um ar-condicionado de última geração pra colocar num fusca."

"Se for como SIR, que nos foi imposto cheio de falhas, creio que vai, sim, ter impacto negativo."
}

Com relação às suas identidades nos contextos de mudança, percebeu-se que os sentimentos de exclusão, controle e imposição vivenciados pelos funcionários mantiveramse constantes ao longo do tempo.

Conforme constatamos nos trechos das entrevistas semiestruturadas com os funcionários transcritos a seguir, eles se sentiam meros coadjuvantes do processo de mudança:

"Acho que eles (gerentes) só querem usar esse GED para monitorar quem está trabalhando e quem não está."

"Porque não foi proposto isso a todos... A proposta não foi essa... Veio de cima para baixo, não veio de baixo pra cima." 


\section{“Irrisória. Minha participação não foi significativa na implantação do GED/WF."}

"Houve muito "disse me disse" sem nenhuma aplicação ou esclarecimento para o grupo. Não foi feita nenhuma reunião para dizer como anda o projeto - ficou restrito nas mãos de poucas pessoas".

"Como tudo aqui na empresa, somos obrigados a aceitar ou fazermos parte... E depois cai tudo no esquecimento, vide o projeto 'Repensar XXX'."

Comentários semelhantes também foram encontrados nos trabalhos realizados em organizações públicas por Zorn (2000), Randall e Procter (2008).

Prosseguindo com a análise do Quadro 2 e considerando agora os discursos dos funcionários com relação aos outros, podemos destacar os seguintes pontos: com relação à alta gerência, verificou-se que, em um segundo momento, esta deixou de ser vista como a única ou maior beneficiária do GED/WF, na medida em que o GED/WF passou a ser visto como instrumento para se fazer justiça aos que trabalham em detrimento dos que estão acomodados.

O GED trará mais transparência com relação às nossas atividades e, para mim, quanto mais transparente melhor, porque se trata de um serviço público e tem que ser aberto, sim, até como uma forma de pressão... De pressão não, como forma de controle mesmo... E tendo um controle maior, as pessoas acabam trabalhando com um pouco mais de cuidado e melhor também. Eu acho que vale aquele velho ditado que diz: o porco só engorda com os olhos dos homens... e então, se deixar solto demais, dificilmente as pessoas vão trabalhar como devem. Claro que eu não vejo isso, também, como uma forma de querer manipular as pessoas, mas se tem um controle maior, fica mais fácil de cobrar. Então, a partir do momento em que pessoas que trabalham menos são mais cobradas, aquelas que estão sobrecarregadas acabam tendo um pouco mais de sossego.

Com relação aos demais colegas do departamento, percebeu-se que houve uma inversão de percepções nos dois momentos, ou seja, com relação à autopercepção, houve a mudança de pessimistas para céticos, enquanto a percepção sobre dos demais colegas mudou de céticos para pessimistas.

Por fim, com relação à equipe do projeto, percebeu-se que esta perdeu credibilidade ao longo do tempo na medida em que passou a ser vista como uma "consultoria tupiniquim", atuando de forma amadora. 


\subsection{A COMUNICAÇÃO}

O discurso dos funcionários com relação à comunicação, por sua vez, continuou praticamente o mesmo ao longo do tempo, ou seja, foi sempre mantido que a comunicação era falha e ineficiente, e atendia aos interesses da cúpula utilizando-se de "palavraschavões" ou do "canto da sereia" para mobilizar a base em prol da mudança. Conforme é verbalizado nos trechos das entrevistas semi-estruturadas com os funcionários transcritos a seguir, a rádio-corredor foi o principal canal de comunicação durante todo o processo de mudança.

"Não tenho condições de responder, pois não tenho informação sobre o objetivo real do GED/WF, uma vez que o que se tem ouvido são apenas 'palavras-chavões', como gerenciamento eletrônico, inovação, fluxo de informações..."

“Ouvi falar que será uma ferramenta poderosa (referindo-se ao GED/WF), mas não me deixo levar facilmente pelo 'canto da sereia'..."

Verificou-se que a comunicação entre a empresa externa contratada para desenvolver a Solução/Ferramenta GED/WF, a equipe do projeto (formada predominantemente por funcionários da área de TI) e a alta gerência do departamento em estudo ocorreu de forma transparente e suficiente (e até excessiva), na medida em que ocorreram muitas reuniões presenciais e virtuais (videoconferências), bate-papos virtuais pelo programa Skype, além de trocas de telefonemas e correios eletrônicos. Além disso, pode também ser considerada eficiente na medida em que ambas as partes estavam bem informadas sobre os objetivos, as diretrizes e o andamento do projeto.

Por outro lado, a comunicação das partes supracitadas com os usuários (funcionários da base do departamento) foi considerada: (a) instrumental, na medida em que não houve uma abertura para que esses indivíduos manifestassem suas opiniões, insatisfações, reclamações; e (b) insuficiente não somente em quantidade, mas também em conteúdo e periodicidade. Como consequência, os indivíduos se viam como meros receptores e, portanto, coadjuvantes no processo de mudança organizacional. Ao serem instigados a dar conselhos e sugestões, por exemplo, os indivíduos expressaram suas 
"mágoas" com relação ao tempo decorrido até que fossem convidados a contribuir direta ou indiretamente com o projeto, conforme podemos exemplificar nos trechos transcritos das entrevistas semiestruturadas com os funcionários a seguir:

"Para implantação do GED/WF, qualquer contribuição agora já é tardia."

"No atual estágio do processo, é difícil dar conselhos."

"Não sei. Como não tenho qualquer informação sobre a implantação do sistema ou formação no assunto, não tenho como responder."

“Estive um mês de férias, mas esse negócio tá meio uma caixinha preta, não tenho recebido nenhuma informação, nenhuma avaliação, não me perguntaram nada, não tô sabendo de nada..."

As "lacunas" na comunicação (grandes períodos de tempo sem divulgar como estava o andamento do projeto) fizeram com que a "rádio-corredor" se tornasse o canal de comunicação predominante entre os indivíduos da base:

"Não me lembro exatamente se tomei conhecimento do GED por meio de "eventuais" comentários das chefias ou em alguma reunião sobre outro tema... Ou se em conversa com terceiros, casualmente presenciada."

"Soube do GED/WF pelos colegas do departamento."

Durante esses "vácuos" comunicacionais, predominou o silêncio tanto da organização para a base (vertical), quanto entre seus componentes (horizontal), que, conforme colocam Robbins, Judge e Sobral (2011), não pode ser interpretado como uma inação ou um não comportamento, nem representar uma falha na comunicação. $\mathrm{Na}$ verdade, o silêncio por parte da alta gerência no caso em estudo foi uma decisão estratégica tomada com o intuito de evitar que as falhas e informações negativas sobre o projeto chegassem à base. Entretanto, o "tiro saiu pela culatra" na medida em que surtiu o efeito contrário, reforçando o que foi defendido por Hernandez e Caldas (2001:p38): “ao tentar preveni-la (resistência à mudança), os agentes organizacionais acabam contribuindo para a sua ocorrência e agravamento". Verificou-se, na prática, que foi exatamente o que ocorreu, pois esse silêncio organizacional vertical foi interpretado pela base como "algo não está 
cheirando bem", dando margem a diversas especulações sobre o fracasso do projeto conforme exemplificamos no trecho da entrevista semi-estruturada com os funcionários transcrito a seguir:

"Eu não tenho nem ouvido as pessoas falarem sobre o GED. No início, falava-se mais do que agora. Em geral, eu já ouvi mais comentários pessimistas do que otimistas. As chefias não falam nada... Isso não está cheirando bem..."

Com relação ao silêncio horizontal (entre os indivíduos da base), vimos que este foi uma forma poderosa de comunicação, na medida em que foram evidenciados sentimentos de ansiedade, medo, insegurança, divergência e frustração, realçados pelo grupo do ARQUIVO - funcionários de nível superior da área de Humanas responsáveis pela administração do acervo documental do departamento -, como forma de os funcionários expressarem sua insatisfação e demonstrarem que estão aborrecidos. Constatou-se que o referido grupo se sentia ameaçado em suas atividades pela digitalização de documentos, que até então estavam em formato de papel, e se sentiram marginalizados durante todo o processo de implantação do GED/WF por não terem sido consultados sobre partes importantes do projeto que englobavam a gestão da informação e de documentos.

A ameaça ao status quo também foi evidenciada sob a forma de resistência por parte de um chefe imediato do departamento, que adotou uma postura de "boicotar" o projeto GED/WF na medida em que se omitia em opiniões, na participação e no envolvimento com o projeto, apoiando os subalternos insatisfeitos e que também se recusavam a participar de sua implementação.

\subsection{O SIGNIFICADO DA MUDANÇA}

Com relação às percepções e significados atribuídos à mudança, observou-se que para alguns ela era considerada como algo importante, imprescindível e inevitável conforme afirma o trecho da entrevista semiestruturada com um funcionário transcrito a seguir:

O GED/WF e nenhuma proposta de sistema de informação é panacéia: além da coisa ter que ser feita bem, administrada e bem conduzida, ou seja, ter sempre R. eletr. estrat. neg., Florianópolis, v.6, n.2, p. 177-216, mai./ago. 2013 
pessoas por trás. Então, o 'vai dar certo', 'vai ser bom', 'vai melhorar' ou 'vai piorar' depende muito da maneira como você vai estar... Do grau de motivação que você consegue impor para as pessoas e também dos objetivos a serem atingidos com a utilização da ferramenta. Eu acho que é uma ferramenta interessante internamente e para os requerentes. Volto a dizer: vai ser bom se for bem conduzido, mas alguns entraves podem surgir.

Para outros, entretanto, não passava de mais um modismo institucional mascarando o objetivo principal de promover a atual gestão:

"Pra mim, esse GED não passa de obra de fachada."

“Acho que será uma atividade a mais... Um modismo que não nos levará a lugar algum."

Durante outros processos de mudança implantados no passado, percebeu-se que também não houve muita abertura para que os funcionários da base pudessem expor suas ansiedades e opinar acerca das estratégias de mudança, o que contribuiu para um sentimento de exclusão e clima de descrença e desconfiança na organização.

O SIR está aí e foi desenvolvido juntamente com o pessoal de TI desde que houve o acidente de Goiânia e houve necessidade de um controle maior das fontes radioativas no país. Mas as pessoas ficaram um pouco ressentidas sob muitos aspectos: a não participação... Quando o banco de dados ficou pronto, ninguém participou e não queriam utilizar. Isso porque somente depois de pronto disseram: 'dá uma olhadinha aí e veja o que acha e como você se insere nesse novo contexto'. Algumas pessoas têm facilidade para assimilar coisas novas, mas outras não.

Com relação ao aspecto comportamental, identificamos os sentimentos de ceticismo e pessimismo encontrados também nos trabalhos de Reichers, Wanous e Austin (1997), Naus, Iterson e Roe (2007) e Dias (2011). A maioria dos funcionários parecia não acreditar muito no sucesso do projeto, fato que se agravou ainda mais com os atrasos no cronograma do projeto:

"Acredito que o mesmo deve ser colocado logo em funcionamento de maneira paralela ao sistema atual para poder corrigir os problemas que com certeza aparecerão - eis a minha sugestão. Minha crítica: está demorando muito a implantação."

"Conselho: eu acho que o mais importante é começar com isso logo, o quanto antes. À medida que o tempo passa, a ideia vai perdendo força, vai ganhando reações negativas, as pessoas começam a desacreditar disso, o aviso do lançamento do GED já foi colocado na homepage da empresa e até agora nada, similar ao que aconteceu com o IEN, que disse que teriam um cíclotron e há 4 anos nada. Isso causa uma imagem negativa, e para reverter é muito complicado... Por 
isso que eu acho que mesmo com problemas, tem que começar. Senão, as pessoas que criticam começam a ganhar força e adeptos."

O ceticismo da base com relação à mudança foi visto pela cúpula da organização e equipe do projeto como traços de resistência à mudança. Entretanto, reforçando a literatura sobre a questão, as pessoas não decidem deliberadamente por se tornarem céticas, elas se transformam com a experiência e com a convivência com outras pessoas que compartilham visões semelhantes, como forma de defesa para evitar o desapontamento quando se antecipam ou preveem que determinada mudança está fadada ao fracasso (REICHERS; WANOUS; AUSTIN, 1997; NAUS; ITERSON; ROE, 2007; DIAS, 2011).

Alguns efeitos e consequências do ceticismo, apontadas nos estudos organizacionais, também foram evidenciados no presente estudo:

(a) Os trechos das entrevistas semi-estruturadas com os funcionários transcritos abaixo nos exemplificam que o ceticismo leva as pessoas a não acreditarem que trabalhando mais e obtendo melhores resultados serão mais bem remuneradas:

“As pessoas estão meio descrentes devido às tentativas frustradas no passado."

"Acho que, de um modo geral, as pessoas estão pessimistas com a estrutura administrativas, pois nem sempre os investimentos são recompensados com resultados."

(b)O depoimento obtido na entrevista semi-estruturada com um funcionário transcrito a seguir exemplifica que o ceticismo diminui a chance dos indivíduos se engajarem em um esforço de mudança, mas estes não necessariamente criarão resistência a ele:

\footnotetext{
“Ninguém tá indo contra, sabe? Isso já é positivo pra caramba. Acho que ninguém ta indo contra... Tá todo mundo parado vendo no que vai dar; mas, por outro, lado ninguém quer colocar a cara na frente e ser o primeiro. É isso... A verdade é essa."
}

No que diz respeito à questão da resistência à mudança, ao longo deste projeto, evidenciou-se que:

(a) Conforme sugerido por Hernandez e Caldas (2001), a resistência pode ocorrer entre os gestores, agentes de mudança e empregados (conforme demonstrado 
por um dos chefes de divisão da empresa); a resistência é tanto individual quanto coletiva (conforme demonstrado pelo grupo do ARQUIVO).

(b)Vários fatores sugeridos por Costa (2006) podem ter contribuído para o surgimento do espírito de resistência identificado neste trabalho, como o preconceito com o resultado (os indivíduos viam o GED/WF como um instrumento de controle das chefias e, logo, como prejudicial ao grupo; o receio de mais trabalho (acreditavam que o GED/WF traria mais trabalho e sem nenhuma compensação); a comunicação ineficiente (a organização não comunicou adequadamente os objetivos, os benefícios e o andamento do projeto); e a revolta dos funcionários (os indivíduos perceberam a mudança como algo imposto de cima para baixo).

No Quadro 4, apresentamos as percepções e discursos do pesquisador, enquanto gerente do projeto e agente da mudança, com relação ao contexto, à sua identidade, aos outros e à comunicação nos dois momentos de coleta de dados qualitativos.

Quadro 4 - Percepções e discurso do pesquisador

\begin{tabular}{|c|c|}
\hline Momento 1 (junho/2007) & Momento 2 (agosto/ 2010) \\
\hline $\begin{array}{l}\text { O CONTEXTO } \\
\text { Exclusão e metodologia do projeto. } \\
\text { Gerência do projeto motivada e composta de novos } \\
\text { servidores. } \\
\text { "Amadorismo". } \\
\text { Greve e clima de apatia. } \\
\text { Recusa da base em participar do projeto. } \\
\text { Foco de resistência no ARQUIVO. }\end{array}$ & $\begin{array}{l}\text { O CONTEXTO } \\
\text { Mudanças na "mudança". } \\
\text { Atraso no projeto. } \\
\text { Gerência do projeto preocupada e desmotivada. } \\
\text { Aumento salarial e clima de euforia. } \\
\text { Recusa da base em utilizar a ferramenta. } \\
\text { Resistência no ARQUIVO e resistência na chefia. }\end{array}$ \\
\hline $\begin{array}{l}\text { EU/NÓS E O CONTEXTO } \\
\text { Eu como "Bombril", "faz-tudo", "quebra-galho". } \\
\text { Quebra de contrato psicológico. } \\
\text { Baixa autoestima. } \\
\text { Ansiedade e insegurança. }\end{array}$ & $\begin{array}{l}\text { EU/NÓS E O CONTEXTO } \\
\text { Eu como gerente de projeto. } \\
\text { Alta autoestima. } \\
\text { Multiplicidade de papéis e responsabilidades. } \\
\text { Crise de identidades. } \\
\text { Problemas pessoais. } \\
\text { Ansiedade, desmotivação, insegurança, medo, estresse, } \\
\text { desgaste físico e psicológico. } \\
\text { Mãe do GED/WF. } \\
\text { "Jegue/WF" = filho feio. }\end{array}$ \\
\hline $\begin{array}{l}\text { EU/NÓS E OS OUTROS } \\
\text { ALTA GERÊNCIA } \\
\text { Parceria, confiança, cumplicidade. }\end{array}$ & $\begin{array}{l}\text { EU/NÓS E OS OUTROS } \\
\text { ALTA GERÊNCIA } \\
\text { Parceria, confiança, cumplicidade, maior proximidade, }\end{array}$ \\
\hline
\end{tabular}




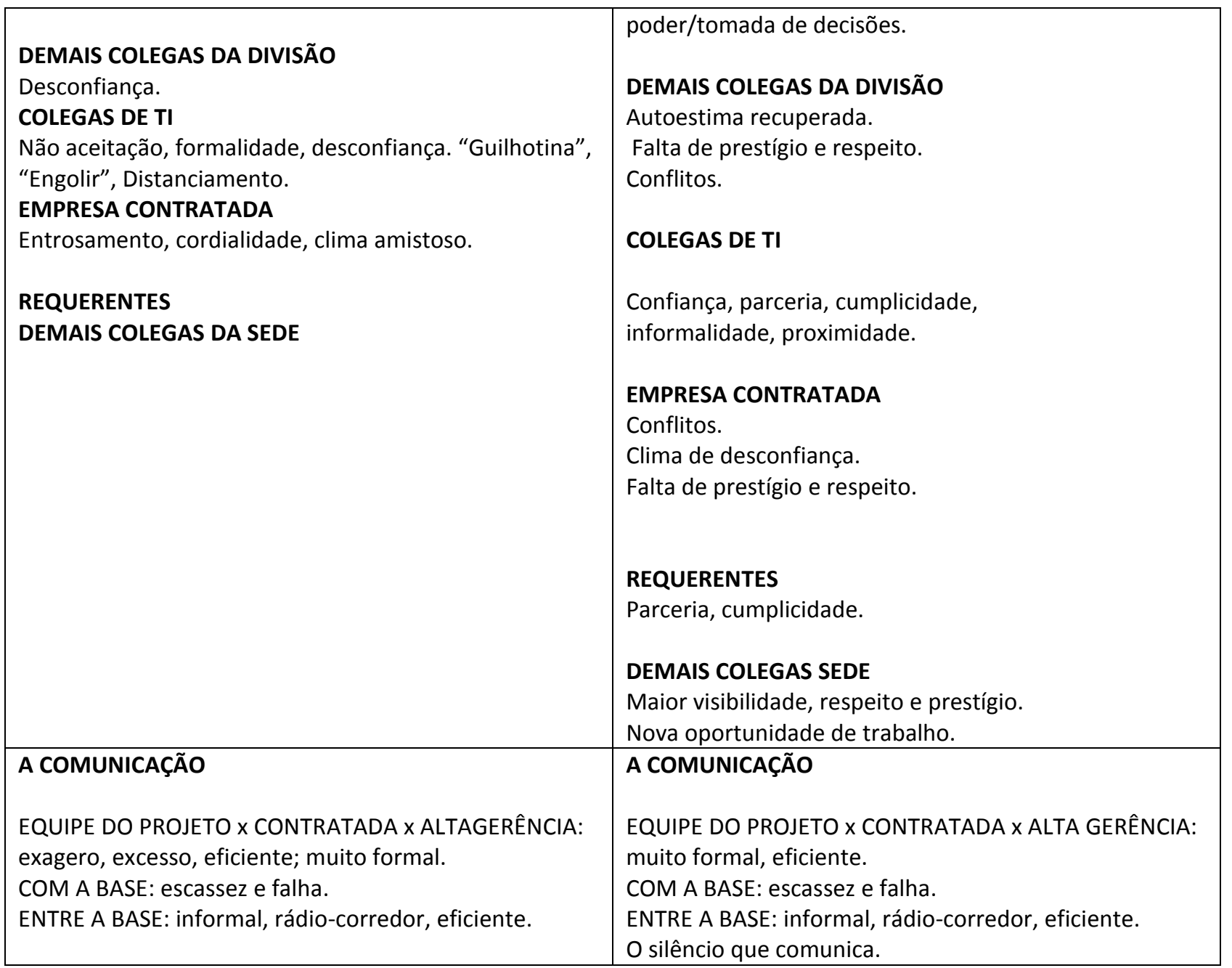

Fonte: Elaborado pelos autores, 2013.

Com relação ao contexto no momento 1 , o pesquisador aponta para a possibilidade de a própria metodologia de projeto utilizada ter contribuído para o sentimento de exclusão experimentado pela maioria dos funcionários, especialmente no início do projeto, na medida em que a inclusão de novos participantes foi feita de forma gradual e de acordo com as etapas e necessidades do projeto. No momento 2, é importante ressaltar as mudanças ocorridas ao longo do projeto, como, por exemplo, as consequências diretas e indiretas de quando ocorreu a mudança do gerente ou de um dos patrocinadores, ou, ainda, do principal analista de sistemas da empresa contratada, que estava desenvolvendo a mudança.

Conclui-se que o processo de mudança sofreu influência do ambiente externo (funcionários da base/usuários finais, aumentos salariais, choques culturais etc.), bem como R. eletr. estrat. neg., Florianópolis, v.6, n.2, p. 177-216, mai./ago. 2013 
do interno (recursos humanos e materiais alocados ao projeto, metodologia, atrasos, falhas etc.), conforme tem ressaltado a literatura do tema (WOOD, 2009; IGBAL, 2011; BANUTUGOMEZ, 2007; KOTTER; COHEN, 2002; SHOOK; ROTH, 2011; JIMMIESON; TERRY; CALLAN, 2004).

Com relação à sua identidade no contexto, um dos pesquisadores relata que ao longo do projeto adquiriu mais confiança e prestígio por parte dos colegas do próprio e de outros departamentos. Essa foi uma mudança radical ocorrida ao logo do projeto na medida em que se passou de um quadro de baixa autoestima e quebra do contrato psicológico a um quadro de autoestima e valorização.

Muito embora esse pesquisador tenha adquirido prestígio ao longo do tempo, adquiriu também mais responsabilidades e teve de lidar com adversidades e conflitos com os quais não parecia estar preparado, além de ter passado por sérios problemas pessoais. Ele serviu de canal para as reclamações, sugestões e todos os outros tipos de manifestações e expressões não somente com relação à mudança em questão, mas também com relação ao departamento e à organização como um todo. Ao perceberem a proximidade do pesquisador com a alta gerência do departamento, alguns chegaram a pedir que levasse determinados recados e sugestões à alta gerência. Chegou-se até mesmo a confundir o instrumento de coleta de dados qualitativos utilizados nesta pesquisa (questionário e entrevistas) como sendo uma iniciativa da alta gerência do departamento para saber a opinião e solicitar sugestões sobre a mudança, conforme constatamos no trecho da entrevista semiestruturada com os funcionários transcrito a seguir:

"Nossa!!! Essa é uma iniciativa inovadora aqui na casa... Nunca vi isso acontecer por aqui antes."

Com relação aos outros, este pesquisador manteve, ao logo do tempo, uma relação de parceria e confiança com a alta cúpula e adquiriu internamente (junto ao departamento e fora dele) certo "poder", prestígio e autonomia na tomada de decisões, mas, em contrapartida, enfraqueceu-se junto à empresa contratada, que somente considerava e acatava as decisões do gerente geral, mesmo sabendo que era ele que o substituía em sua ausência.

R. eletr. estrat. neg., Florianópolis, v.6, n.2, p. 177-216, mai./ago. 2013 


\section{CONCLUSÕES}

Face à complexidade de um processo de mudança organizacional, seja ela planejada ou não, o presente trabalho analisou as diferentes dimensões que afetam o modo como a mudança é interpretada e construída coletivamente. Para tanto, adotou-se um quadro referencial, proposto por Silva (2001), que privilegiou as seguintes dimensões: a percepção dos indivíduos sobre o contexto; os indivíduos e suas identidades; as relações com as outras identidades na organização; e a percepção sobre a comunicação.

O caso estudado identificou algumas percepções dos indivíduos que atuam na base e nos níveis intermediários da organização, contribuindo para um melhor entendimento sobre como os indivíduos e grupos reagem em um contexto de mudança organizacional, levando-se em consideração seus sentimentos, suas expectativas, suas possibilidades de participação e seu engajamento.

Partindo-se das observações decorrentes da análise dos discursos dos entrevistados e da observação-participante de um dos pesquisadores, as conclusões podem ser resumidas da seguinte forma: com relação ao papel da comunicação na construção do significado em processos de mudanças organizacionais planejadas, confirmam-se os estudos de Brutus e Greguras (2008); Fiol (2002), Gioia, Schultz e Corley (2000); Junior, Mateus e Souto (2008), Howard (2006), Hope (2010) e Maitlis e Sonenshein (2010). Observou-se que:

$\checkmark$ a mudança é um processo recursivo de construção social, no qual novas realidades são criadas, sustentadas e modificadas no processo de comunicação; $\checkmark$ a comunicação não pode ser vista como uma simples ferramenta para promover a compreensão e a adesão, mas, sim, como o próprio meio em que a construção de significado da mudança acontece;

$\checkmark$ a organização precisa se esforçar para comunicar adequadamente os seus objetivos, motivos e expectativas acerca da mudança a ser implantada.

Com relação à fragilidade de alguns pressupostos sobre a gestão de mudanças e supostas resistências:

R. eletr. estrat. neg., Florianópolis, v.6, n.2, p. 177-216, mai./ago. 2013 
$\checkmark$ contrariando o pressuposto clássico de que os empregados da base são os atores organizacionais com maior probabilidade de resistirem à mudança, verificou-se que a resistência à mudança pode ocorrer entre os gestores, agentes de mudança e empregados, conforme colocado por Hernandez e Caldas (2001); $\checkmark$ alguns modelos tratam a resistência à mudança como um fenômeno individual, enquanto outros o abordam como sendo um fenômeno coletivo. Neste trabalho, da mesma forma como foi identificado por Costa (2006) e Becher (2003), constatou-se que a resistência à mudança é tanto individual quanto coletiva;

$\checkmark$ conforme assinala Wood (2009), as mudanças não seguem uma fórmula predeterminada e, portanto, não existe receita para implementar uma mudança de sucesso;

$\checkmark$ é preciso considerar o contexto, ou seja, em que momento e sob quais condições se manifestam as resistências, visto que as opiniões e percepções dos indivíduos variam conforme as variações do ambiente organizacional;

$\checkmark$ os dirigentes das organizações, ao ocultarem uma informação negativa aos funcionários por medo de possíveis resistências, acabam contribuindo para o fenômeno;

$\checkmark$ os indivíduos e grupos adotam certos mecanismos de defesa contra a mudança, seja por medo ou insegurança (ameaça ao status quo), que não são compreendidos e/ou valorizados pela organização;

$\checkmark$ compreender as resistências à mudança significa compreender quem são, de fato, os indivíduos que dela participam, como interagem e qual o significado que ela tem para eles.

$\checkmark$ conforme afirma Giroux (1993:10), “mudar a organização, é mudar os comportamentos das pessoas e as relações entre elas. É, ao mesmo tempo, mudar sua posição na rede de engajamento, seu contexto de criação de significação. É tocar sua identidade, seu cotidiano". Nessa perspectiva, a resistência à mudança e os problemas de comunicação não devem ser vistos como barreiras à mudança, mas como produtos naturais da mudança. 
Logo, a mudança, mesmo quando intencional, deve ser vista sob a ótica de um processo social de construção de uma nova realidade e, para que isso ocorra, é preciso dar voz a todos os sujeitos organizacionais. É justamente com relação a esse ponto que se deve chamar a atenção para a necessidade de que as organizações programem um conjunto de iniciativas que estimulem a compreensão e a adesão das pessoas com relação ao processo de mudança. Para isso, deve-se levar em consideração o fato de que grande parte da comunicação organizacional, senão a maior parte, acontece de modo horizontal, ou seja, nas interações dos indivíduos, no dia a dia, e de que, portanto, deve-se atentar não somente para o discurso organizacional, mas também às práticas que, por vezes, comunicam muito mais aos indivíduos e grupos.

Tais discussões trazem à tona também a necessidade de que a organização adote um conjunto de iniciativas que estimulem a compreensão e a adesão das pessoas com relação ao processo de mudança.

Por fim, sugerimos que novos estudos de caso longitudinais sejam realizados na área de mudança organizacional com o objetivo de auxiliar o meio acadêmico e gerencial na compreensão de fenômenos comportamentais adotados por indivíduos e grupos em contextos de mudanças organizacionais planejadas, e, além disso, em suas relações com as percepções desses indivíduos e grupos em função do tempo e do contexto.

\section{COMMUNICATION AND MEANING CONSTRUCTION IN PLANNED ORGANIZATIONAL CHANGES: THE EMPLOYEE PERCEPTIONS OF A BRAZILIAN GOVERNMENTAL ORGANIZATION.}

\section{ABSTRACT}

A lot of researchers and managers have been trying to find the factors that affect the success of organizational change processes. One of the most mentioned factors in literature about this theme is the 'resistance' to change on the part of some organizational actors, in special the ones belonging to the lower hierarchical levels. How these individuals realize themselves and the other in organizational change processes? How they realize the content and management of the change? What is the role of communication in a change context? This R. eletr. estrat. neg., Florianópolis, v.6, n.2, p. 177-216, mai./ago. 2013 
work aims to contribute to a better understanding about the meaning construction process for individuals and groups in planned organizational changes and its relationship with the communication and behavior aspects presented for them. For this purpose, it was conducted a case study in a Brazilian public organization that was performing an organizational change in the Technology of Information area: implantation of an electronic management system of documents and workflow. The results show that organizational change is sensitive to the relational aspect. Action and human behavior in organizations should be considered as products of communication process and determining factor in the construction of meanings and of individual and collective identities.

Keywords: Organizational Change. Organizational Communication. Resistance to Change. Meaning Construction. Organizational Identity.

\section{REFERÊNCIAS}

ASHFORTH B.E.; MAEL, F.A. The Power of resistance: Sustaining Valued Identities. In: R.M. Kramer, R. M.; NEALE, M.A. (Orgs.). Power and Influence in Organizations: 89-120. Thousand Oaks: sage, 1998.

AHRENS, C.; CHAPMAN T. The structuration of legitimate performance measures and management: day-to-day contests of accountability in a U.K. restaurant chain. Management Accounting Research, June, 13, n. 2, p. 151-171. 2002.

ANTONI, C. H. A. Motivational perspective on change processes and outcomes: Research Note. European Journal of Work and Organizational Psychology, The official journal of the European Association of Work and Organizational Psychology,v. 13, n. 2, p. 197-216. 2004.

ARMENAKIS, A. A.; HARRIS, S. G. Crafting a change message to create transformational readiness. Journal of Organizational Change Management, vol.15, Issue 2, p. 169-183. 2002.

BALOGUN, J. Managing change: steering a course between intended strategies and unanticipated outcomes. Long Range Planning, February, vol. 39, Issue 1, p. 29-49. 2006.

BANUTU-GOMEZ, M. B.; BANUTU-GOMEZ, S. M. T. Leadership and Organizational Change in a Competitive Environment. Business Renaissance Quarterly, 2, p.69-90, 2007. 
BARON, R. S. So Right It's Wrong: Groupthink and the Ubiquitous Nature of Polarized Group Decision Making. Advances in Experimental Social Psychology, Elsevier, vol. 37, p. 219-253. 2005.

BAXTER, W. F.; CHUA J. Alternative management accounting research - whence and whither. Accounting, Organizations and Society, February-April, v. 28, Issues 2/3, p. 97-126. 2003.

BECHER, S. B. A. Language Matters in Management: Creating Sustainable Competitive Advantage with the Right Talk. In: DELENER, N.; CHAO, C. Challenging the frontiers in global business and technology: Implementation of Changes in Values, Strategy and Policy. International Conference of the Global Business and Technology Association, (GBATA), p. 186-193, 2003.

BEER, M.; NOHRIA, N. Cracking the code of change, Harvard Business Review, June-July, vol. 78, n. 3, p. 133-141. 2000.

BERNERTH, J. Expanding our understanding of the change message. Human Resource Development Review, March, vol. 3, p. 36-52. 2004.

BORDIA, P.; HOBMAN, E.; JONES, E.; GALLOIS, C.; CALLAN, V.J. Uncertainty during organizational change: Types, consequences, and management strategies. Journal of Business and Psychology, 18(4), 507-532, 2004.

BOVEY, W. H.; HEDE, A. Resistance to Organizational change: the role of defence mechanisms Journal of Managerial Psychology, Emerald 16,vol.16, n. 7, p. 534-548. 2001.

BROWER, R.S.; ABOLAFIA, M.Y. The Structural embeddedness of resistance among public managers. Group and Organizational Management, 20:149-166,1995.

BRYANT, M.; COX, J. W. Conversion stories as shifting narratives of organizational change. Journal of Organizational Change Management, vol.17, n. 6, p. 578-592. 2004.

BRUTUS, S.; GREGURAS, G. J. Self-construals, motivation and feedback-seeking behaviors. International Journal of Selection and Assessment, September, vol. 16, Issue 3, p. 282-291. 2008.

BUCHANAN, D. You stab my back, l'll stab yours: management experience and perceptions of organization political behavior. British Journal of Management, March, vol. 19, n. 1, p. 4964. 2008.

CHENG J. S. L.; PETROVIC-LAZAREVIC, S. P. L. The Flair of Resistance to Change: An EmployeeCentred Perspective. Monash Business Review, August, vol. 1, n. 1, 2005. 
CHRUSCIEL, D. Considerations of emotional intelligence in dealing with change decision management. Management Decision, Vol. 44, Issue 5, p. 644-657. 2006.

CLEGG, S. Weber and Foucault: Social Theory for the Study of Organizations. Organization 1(1): 149-78, 1994.

CINITE, I.; DUXBUR,Y L. E.; HIGGINS, C. Measurement of Perceived Organizational Readiness for Change in the Public Sector. British Journal of Management, June, vol. 20, Issue 2, p. 265-277. 2009.

COGHLAN, D. A Person-centered Approach to Dealing with Resistance to Change, Leadership \& Organization Development Journal, Vol. 14 Issue 4, pp.10 - 14, 1993

$\mathrm{COCH}$, L.; FRENCH, J. R. P. Jr. Overcoming resistance to change. Human Relations, vol. 1, p. 512-532. 1948.

COHEN, A.D. Strategies in Learning and Using a Second Language, London and New York: Longman, 1998

COLLIER P. M. The power of accounting: a field study of local financial management in a police force. Management Accounting Research, December, vol. 12, n. 4, p. 465-486, 2001.

CONNER, D. R. Gerenciando na velocidade da mudança: como gerentes resilientes são bem sucedidos e prosperam onde outros fracassam. Rio de Janeiro: Infobook, 1995.

CONRAD, L. A structuration analysis of accounting systems and systems of accountability in the privatised gas industry. Critical Perspectives on Accounting, January, vol. 16, n. 1, p. 126. 2005.

COSTA, S. B. A. B. O Significado da Mudança ou a Mudança de Significado? Análise da Implantação de Modelos de Gestão de Pessoas por Competências. 2006. Tese (Doutorado em Administração). Departamento de Administração, IAG/ PUC-Rio, Rio de Janeiro, 2006.

DAWSON, P. Understanding Organizational Change: The Contemporary Experience of People at Work. London: Sage, 2003.

DIAS, M. I. R. Cinismo Organizacional. 2011. Dissertação (Mestrado em Psicologia) Universidade Lusófona de Humanidades e Psicologia, Faculdade de Psicologia, Lisboa, 2011. Disponível em:

<http://recil.grupolusofona.pt/bitstream/handle/10437/1732/MARIA\%20INES\%20DIAS.pdf? sequence=1>. Acesso em: 12 abr. 2013. 
DILLARD, J. T.; RIGSBY, C.; GOODMAN, J. F. The making and remaking of organization context: duality and the institutionalization process. Accounting, Auditing \& Accountability Journal, Vol. 17, n. 4, p. 506-542. 2004

DYCK, L. R.; CARON, A.; ARON, D. Working on positive emotional attractor through training in health care. Journal of Management Development, Vol.25, n. 7, p. 671-688. 2006.

ELVING, W. J. L. The role of communication in organizational change. Corporate Communication: An International Journal, Vol.10, n. 2, p. 129-138. 2005.

ERTURK, A. A trust-based approach to promote employees openness to organizational change in Turkey. International Journal of Manpower, v. 29, n. 5, p. 462-483. 2008.

FAIRHURST, G. T.; PUTNAM, L. Organizations as discursive constructions. Communication Theory, Vol. 14, p. 5-26. 2004.

FERNANDES, K. R.; ZANELLI, J. C. O Processo de Construção e Reconstrução das Identidades dos Indivíduos nas Organizações. Revista de Administração Contemporânea, Curitiba, JanMarço, v. 10, n. 1, p. 55-72, 2006.

FIOL, C.M. Capitalizing on Paradox: The Role of Language in Transforming Organizational Identities, Organization Science, November/December,vol. 13 no. 6 653-666, 2002.

FRAHM, J.; BROWN, K. First steps: linking change communication to change receptivity. Journal of Organizational Change Management, Vol.20, n. 3, p. 370-387, 2007.

GEORGE, J. M.; JONES, G. R. Towards a process model of individual change in organizations. Human Relations, April, v.54, 419-444, 2001.

GIANGRECO A.; PECCEI, R. The nature and antecedents of middle manager resistance to change: evidence from an Italian context International Journal of Human Resource Management October,16:10 , 1812-1829,2005

GIDDENS, A. The Constitution of Society. Cambridge: Polity Press, 1984.

GIOIA, D. A.; SCHULTZ, M.; CORLEY, K. G. Organizational identity, image and adaptive instability. Academy of Management Review, January 1,v. 25, n. 1, p. 63-81. 2000.

GIROUX, N. Communication et Changement dans les Organisations. Communication et Organisation, n. 3, p. 9-18, maio. 1993.

. La Communication dans la Mise en Oeuvre du Changement. Management International. Montréal: CETAI/École des Hautes Études Commerciales (HEC), v. 3, n. 1, p. 114. 1998. 
GLADWELL, M. Blink: The power of thinking without thinking. New York: Little, Brown, 2005

GORDON, K. The importance of communication in implementing organizational change: a review of the literature for information organizations. San Jose State University, School of Library and Information Science, USA, 2006

HERKENHOFF, L. Culturally tuned emotional intelligence: an effective change management tool. Strategic change, March-April, vol. 13, Issue 2, p. 73-81, 2004.

HERNANDEZ, J. M. C.; CALDAS, M. P. Resistência à mudança: uma revisão crítica. Revista de Administração de Empresas, São Paulo, v. 41, n. 2, p. 31-45, abr./jun. 2001.

HERSCOVITCH, L.; MEYER, J. P. Commitment to organizational change: Extension of a three component model. Journal of Applied Psychology, v. 87, n. 3, p. 474-487, 2002.

HOGG, M. A.; TERRY, D. J. Social identity and self-categorization processes in organizational contexts. Academy of Management Review, January, Vol. 25, p. 121-140. 2000.

HOLBECHE, L. Understanding Change: Theory, Implementation and Success. London: Butterworth-Heinemann, 2006.

HOPE, O. The Politics of Middle Management Sensemaking and Sensegiving. Journal of Change Management, June,Vol.10, n. 2, p. 195-215, 2010.

HOWARD, A. Positive and negative emotional attractors and intentional change. Journal of Management Development, Vol. 25, n. 7, p. 657-670, 2006.

HUY, Q.Emotional apabilitye, emotional intelligence, and radical change. Academy of Management Review, 24:325-345, 1999.

IGBAL, R. Impact of Organizational Change to Achieve Competitive Edge. European Journal of Business and Management, July, Vol.3, n. 4. 2011.

INALHAN, G. Attachments: The unrecognized link between employees and their workplace (in change management projects). Journal of corporate real estate, Vol. 11, n. 1, p. 17-37. 2009.

JACK L. Stocks of knowledge, simplification and unintended consequences: the persistence of post-war accounting practices in UK agriculture. Management Accounting Research, Vol. 16, n. 1, p. 59-79. 2005.

JACK L. Stocks of knowledge, simplification and unintended consequences: the persistence of post-war accounting practices in UK agriculture. Management Accounting Research, March, vol. 16, n. 1, p. 59-79. 2005. 
JERMIER, J.M.; KNIGHTS, D.; NORD, W.R. (Eds) Resistance and Power in Organizations. London: Routledge, 1994.

JIAN, G. Unpacking Unintended Consequences in Planned Organizational Change: A Process Model. Management Communication Quarterly, Vol. 21, n. 1, p. 5-28, ago. 2007.

JIMMIESON N. L.; TERRY D. J.; CALLAN V. J. A Longitudinal Study of Employee Adaptation to Organizational Change: The Role of Change-Related Information and Change-Related SelfEfficacy. Journal of Occupational Health Psychology, January, vol. 9, n. 1, p. 11-27. 2004.

JONES, E.; WATSON, B., GARDNER, J.; GALLOIS, C Organizational communication: challenges for the new century. Journal of Communication, Vol.54, p. 722-50. 2004.

JUNIOR, E. D.; MATEUS, J.; SOUTO, S. Mudança Organizacional: Técnicas empregadas para minimizar impactos e gerar comprometimento. Revista Caderno de Administração, Faculdade Salesiana de Educação, Ano 1, v. 1, n. 2,Julho-Dezembro. 2008. Disponível em: http://www.fsma.edu.br/cadernos/Artigos/V2_artigo02.pdf. Acesso em 27/07/2012.

KAVANAGH, M. H.; ASHKANASY, N. M. The impact of leadership and change management strategy on organizational culture and individual acceptance of change during a merger. British Journal of Management, March, Vol. 17, Issue 1 p. S81-S103. 2006.

KIRSCH, C.; CHELLIAH, J.; PARRY W. Drivers of change: a contemporary model. Journal of Business Strategy, March, Vol. 32, n. 2, p. 13-20. 2011.

KOHLER, J. M.; MUNZ D. C.; GRAWITCH M. J. Test of a dynamic stress model for organizational change: Do males and females require different models? International Association of Applied Psychology, April, Vol. 55, Issue 2, p.168-191. 2006

KORTH B. Critical qualitative research as consciousness raising: the dialogic texts of researcher/research interactions. Qualitative Inquiry, Vol. 8, Issue 3, p. 381-403. 2002.

KOTTER, J. P.; COHEN, D. S. The Heart of Change. Boston: Harvard Business School Press, 2002.

KRISHNAKUMAR, S.; NECK, C. The what, why and how of spirituality in the workplace. Journal of Managerial Psychology, Vol. 17, Issue 3, p. 153-164. 2002.

LAYDER D. Understanding Social Theory. London: Sage Publications, 1994.

LEWIN, K. Frontiers in group dynamics: concept, method and reality in social science; social equilibria and social change. Human Relations, Vol. 1, 5-41,1947. 
LINES, R. The Structure and Function of Attitudes Toward Organizational Change. Human Resource Development Review, Vol. 4, Issue 1, p. 8-32. 2005.

MAGUIRE, S.; HARDY, C. Discourse and Deinstitutionalization: the Decline of DDT, Academy Management Journal, February 1, vol. 52 no. 1 148-178, 2009.

MAITLIS, S.; SONENSHEI, S. Sensemaking in Crisis and Change: Inspiration and Insights From Weick (1988) Journal of Management Studies, May, Volume 47, Issue 3, 551-580, 2010.

MAURER, T., MITCHELL, D.; GODSEY, C. Employees' goal emphasis, self-efficacy, attitudes, and development activity following 360-degree feedback. Presented at the Annual Conference of the Society for Industrial and Organizational Psychology (SIOP), Inc., San Diego, 1996.

MEYER, C. B. Destructive dynamics of middle management intervention in postmerger processes. The Journal of Applied Behavioral Science, December, Vol. 42, n. 4, p. 397-419. 2006.

MILLIGAN, J. M. Loss of site: organizational site moves as organizational deaths. International Journal of Sociology and Social Policy, Jun 1, Volume 23 (6/7):38. 2003.

MORRISON, E. W.; MILLIKEN, F. J. Organization Silence: a Barrier to Change and Development in a Pluralistic World. Academy of Management Review, October, Vol. 25, $\mathrm{n}$. 4, p. 706-725. 2000.

NAUS, F.; ITERSON, A.; ROE, R. Organizational Cynicism: Extending the exit, Voice, Loyalty and Neglect Model of Employees' Responses to Adverse Conditions in Workplace. Human Relations, Vol.60, 683. Sage Pub. 2007.

NEIVA, E. R. Percepção de mudança organizacional: o papel das atitudes e das características organizacionais. Tese de Doutorado, Universidade de Brasília, DF, Brasil, 2004.

NONAS, K. Vision versus Reality in Organizational Change. National Institute for Working Life/West. 2005. Disponível em: <http://ebib.arbetslivsinstitutet.se/ah/2005/ah_2005.pdf>. Acesso em: 14 jan. 2013

OREG, S.; Personality, context and resistance to organizational change. European Journal of Work and Organizational Psychology, Vol. 15, Issue 1, p. 73-101. 2006.

OSWICK, C., GRANT, D., MARSHAK, R. J., COX, J. W. Organizational discourse and change: Positions, perspectives, progress, and prospects. Journal or Applied Behavioral Science, Vol. 46, Issue 1, p. 8-15. 2010. 
PARISH, J. T.; CADWALLADER, S.; BUSCH, P. Want to, need to, ought to: employee commitment to organizational change. Journal of Organizational Change Management, Vol. 21, n. 1, p. 35-52. 2008.

PENTEADO, A. S.; SILVA, J. R. G. A Tentativa de Reforço de um Perfil Desejado de Funcionário e seus Efeitos Sobre a Orientação das Identidades nas Situações de Mudança Organizacional. In: ENCONTRO NACIONAL DOS PROGRAMAS DE PÓS-GRADUAÇÃO EM ADMINISTRAÇÃO, 28., Curitiba, 2004. Anais. Curitiba: ANPAD, 2004.

PETTIGREW, A. M.; WOODMAN, R. W.; CAMERON, K. S. Studying organizational change and development: challenges for future research. Academy of Management Journal, August, vol. 44, n. 4, p. 697-71. 2001.

PHILLIPS, N.; LAWRENCE, T. B.; HARDY, C. Discourse and institutions. Academy of Management Review, October 1, vol. 29, n. 4 ,p. 635-652. 2004.

PIDERIT, S. K. Rethinking resistance and recognizing ambivalence: A multidimensional view of attitudes toward an organizational change. Academy of Management Review, October 1, vol. 25, n. 4, p. 783-794. 2000.

QUIRKE, B. Communicating corporate change. London: McGraw Hill, 1996.

RAFFERTY, A. E.; RESTUBOG, S. L. D. The impact of change process and context on reactions to change and turnover during a merger. Journal of Management, September, vol. 36, n.5 p. 1309-1338. 2010.

RANDALL, J.; PROCTER, S. Ambiguity and ambivalence: Senior managements' accounts of organizational change in a restructured government department. Journal of Organizational Change Management, Emerald Group Publishing Limited, Vol. 21, n. 6, p. 686-700. 2008.

REICHERS, A. E.; WANOUS, J. P.; AUSTIN, J. T. Understanding and Managing Cynicism About Organizational Change. Academy of Management Executive, February 1, vol. 11, n. 1. 1997.

ROBBINS, S. P.; JUDGE, T. A.; SOBRAL, F. Comportamento Organizacional: teoria e prática no cotexto brasileiro. 14. ed. São Paulo: Pearson Prentice Hall, 2011.

ROSE J. Evaluating the Contribution of Structuration Theory to the Information Systems Discipline. 1998. Disponível em:

<http://www.cs.auc.dk/ jeremy/pdf\%20files/ECIS1998.pdf>. Acesso em: 14 jan. 2012.

ROULEAU, L. Micro-practices of strategic sensemaking and sensegiving: how middle managers interpret and sell change every day. Journal of Management Studies, November, vol. 42, n. 7, p. 1413-1441. 2005. 
ROUSSEAU, D. M. Psychological and implied contracts in organizations. Employee Rights and Responsibilities Journal, v. Vol. 2, n. 2, p. 121-139. 1989.

SCHALK, R.; CAMPBELL, J. W.; FREESE, C. Change and employee behavior. Leadership and Organization Development Journal, MCB UP Ltd Publisher, vol. 19, n. 3, p. 157-163. 1998.

SCHWARZ, G. M. Positioning hierarchy in enterprise system change. New Technology, Work and Employment, November, vol. 21, issue 3, p. 252-265. 2006.

SCHWARZ, G. M.; WATSON, B. M.; CALLAN, V. J. Talking Up Failure: How Discourse Can Signal Failure to Change. Management Communication Quarterly, April , vol.35, Issue 4, p.10171042.2011

SILVA, J. R. G. Comunicação e mudança em organizações brasileiras: desvendando um quadro de referência sob a ótica do sujeito e da reconstrução de identidades. 2001. Tese (Doutorado em Administração). Departamento de Administração da PUC/RJ, Rio de Janeiro, 2001.

SIRKIN, H. L.; KEENAN, P.; JACKSON, A. The hard side of change management. Harvard Business Review, Vol. 83, n. 10, p. 108-118. 2005.

SOMMER, K. L.; BAUMEISTER, R. F. The construction of meaning from life events: empirical studies of personal narratives. In: Wong PTP, Fry PS eds. The human quest for meaning. A handbook of psychological research and clinical applications. Mahwah, NJ: Lawrence Erlbaum Associates, p.143-61. 1998.

SOIN, K., SEAL, W., CULLEN, J. ABC and Organizational Change: An Institutional Perspective. Management Accounting Research. Vol. 13, p. 249-271, 2002.

SONENSHEIN, S. We're Changing - Or Are We? Untangling The Role of Progressive, Regressive, And Stability Narratives During Strategic Change Implementation. Academy of Management Journal, June 1, vol. 53, n. 3, p. 477-512. 2010.

SHOOK, L.; ROTH, G. Downsizings, mergers and acquisitions: Perspectives of human resource development practitioners. Journal of European Industrial Training, 35(2), 135153, 2011.

SOUMYAJA, D.; KAMALANABHAN, T. J.; BHATTACHARYYA, S. Employee Readiness to Change and Individual Intelligence: The Facilitating Role of Process and Contextual factors.

International Journal of Business Insights \& Transformation, Vol. 4, n. 2, abr./set., p. 1151232011.

STANLEY, D. J.; MEYER, J. P.; TOPOLNYTSKY, L. Employee cynicism and resistance to organizational change. Journal of Business and Psychology, Vol. 19, n. 4, p. 429-459. 2005. 
STENSAKER,I ; FALKENBERG;J. Making sense of different responses to corporate change, Human Relations, January, vol. 60 no. 1,p. 137-177, 2007

SVENINGSSON, S.; ALVESSON, M. Managing managerial identities: Organizational fragmentation, discourse and identity struggle. Human Relations, October, vol. 56, n.10, p. 1163-1193. 2003.

TAYLOR, J. R., FLANAGIN, A. J., CHENEY, G., \& SEIBOLD, D.R., J. R. Organizational communication research: key moments, central concerns, and future challenges. In: GUDYKUNST, W. B. Communication Yearbook, Vol. 24, p. 99-137. 2001.

THIOLLENT, M. Metodologia da Pesquisa-ação. 14. ed. São Paulo: Cortez, 2005.

TOWNLEY, B. Reason's Neglect: Rationality and Organizing. Oxford: Oxford University Press, 2008.

TSOUKAS, H. Afterword: Why language matters in the analysis of organizational change. Journal of Organizational Change Management, Emerald Group Publishing Limited, vol.18, Issue 1, p. 96-104. 2005.

TUSHMAN, M.;ROMNELLI,E. Organization evolution: a metamorphosis model of convergence and reorientation. In L.L. Cummings and Barry M. Staw (eds.), Research in Organizational Behavior, 7:171-222.Greenwich,CT:JAI Press,1985

VAKOLA, M.; NIKOLAOU, I. Attitudes towards organizational change: What is the role of employees stress and commitment? Employee Relations, Emerald Group Publishing Limited, vol. 27, n. 2, p. 160-174. 2005.

VINCE, R.; BROUSSINE, M. Paradox, defense, and attachment: Accessing and working with emotions and relations underlying organizational change. Organization Studies, January, vol. 17, n.1,p. 1-21. 1996.

WADELL, D.; SOHAL, A. Resistance: a constructive tool for change management. Management Decision, Vol. 36, n. 8, p. 543-8. 1998.

WANBERG, C. R.; BANAS, J. T. Predictors and outcomes of openness to changes in a reorganizing workplace. Journal of Applied Psychology, February, vol.85, n. 1, p. 132-142. 2000.

WASHINGTON, M.; HACKER, M. Why change fails: knowledge counts. Leadership and Organizational Development Journal, Emerald Group Publishing Limited, vol. 26, Issue 5, p. 400-411. 2005. 
WEICK, K. E.; QUINN, R. E. Organizational Change and development. Annual Review of Psychology, February, vol. 50, p. 361-386. 1999.

WHELAN-BERRY, K. S.; GORDON, J. R.; HININGS, C. R. Strengthening Organizational Change Process. The Journal of Applied Science, NTL Institute Pub., vol. 39, n. 2, p. 186-207, jun. 2003.

WIND, J. Y.; MAIN, J. Provocar Mudanças: Como as melhores empresas estão se preparando para o século XXI. Rio de Janeiro: Qualitymark, 2002.

WOOD Jr., T. Mudança Organizacional. 5. ed. São Paulo: Atlas, 2009.

ZORN, T. E.; PAGE, D. J.; CHENEY, G. Nuts about Change: Multiple Perspectives on ChangeOriented Communication in a Public Sector Organization. Management Communication Quarterly, May, vol. 13, n. 4, p. 515-566. 2000. 